\title{
Explaining Child Mortality in Rural Nigeria
}

\author{
Oluwakemi Adeola Obayelu* \\ Department of Agricultural Economics, University of Ibadan, Nigeria
}

*Corresponding Author: Oluwakemi Adeola Obayelu, Department of Agricultural Economics, University of Ibadan, Nigeria, Email: jkemmyade@yahoo.co.uk

\begin{abstract}
Child mortality remains a major public health challenge in Nigeria. Despite the substantial global decline in childhood deaths, the country has failed to make significant progress in checking the rising mortality rate among the under-five. The focus of most studies on child mortality was not on rural Nigeria, which is well-known for poor health facilities. This study assessed spatial incidence and identify socioeconomic pre-disposing factors of child mortality rate in rural Nigeria using 2013 Demographic Health Survey (DHS). Data were analysed using descriptive statistics and Tobit regression model. Mean age of the mothers was 28.8+9.7 years and a typical rural mother was a teenager at first birth except in the South-east and South-west. A higher proportion of the mothers were poor (54.5\%). Child mortality was more prominent among the women in the Northern region with Northwest (31.2\%) followed by the North east (21.5\%) while South-east region had the least child mortality (6.0\%). About a half of the rural mothers had formal education and child mortality sharply declined as mother's educational level increases. Incidence of child mortality was highest among poor married mothers that started child bearing as teenagers. Age, mothers' educational attainment, household size, marital status, mother's age at first birth, occupation, wealth index, sources of drinking water, place of delivery and toilet facility significantly explained child mortality in rural Nigeria.
\end{abstract}

Keywords: Under-five child, mortality rate, rural Nigeria, geopolitical zones, mothers' characteristics

\section{INTRODUCTION}

Child mortality is a fundamental measurement of a country's level of socio-economic development. Under-five mortality rate represents the probability of a newborn child per 1000 will not attain age five. For instance, 60 percent of under-five mortality can be attributed to deaths that occur during the first year of life, of which the first 24 hours of life is the most vulnerable period, followed by the first week and then the first month (Marx et al., 2005). Almost half of the child mortality $(42 \%)$ in the world occurs in Africa and about 25,000 underfive children that die each day are concentrated in sub-Saharan Africa and South Asia (WHO, 2011). Under-five mortality rate is generally 29 times higher in developing nations compared to developed countries (Black and Liu, 2012; Gambrah and Adzadu, 2013; Marx et al., 2005). Globally, under-five mortality has dropped significantly by almost 45 percent between 2009 and 2011. It reduced from 90 deaths per 1000 live births in 1990 to 48 deaths in 2012; but the rate still remains very high in sub-Saharan
Africa (from 177 to 98 deaths). In 2012, approximately half the world's estimated 6.6 million deaths in children aged less than 5 years occurred in sub-Saharan Africa, and Nigeria accounted for approximately $13 \%$ of these deaths (UNICEF, 2014).

Child mortality remains a major public health challenge in Nigeria. Despite the substantial global decline in childhood deaths, the country has failed to make significant progress in checking the rising mortality rate among the under-five. Currently, the country has the highest reported number of under-five deaths in Africa and ranks as having the second highest number (after India) worldwide. Up to 20 per cent of child deaths in sub-Saharan Africa still occur in Nigeria (World Bank, 2013). Also, the Multiple Indicator Cluster Survey (MICS) report indicated that under-five mortality in Nigeria increased from 138 per 1,000 live births in 2007 to 158 per 1,000 live births in 2011 (National Bureau of Statistics, 2011). Nearly one million aged under-five children die in Nigeria annually and more than $60 \%$ of these deaths occur 
between 1 and 59 months of life (UNICEF, 2014). As a result of this marginal reduction in childhood deaths, Nigeria was not able achieve the Millennium Development Goal target of 76 deaths per 1000 live births by 2015 .

Moreover, causes of child mortality are multifactorial, especially in developing countries, where there are great variations between social, economic, demographical and geographical groups of people. Among the suspected factors that have contributed to drastic reduction of under-5 mortality in advanced economies include but not limited to improvement in socioeconomic and environmental conditions and strategic implementation of child survival interventions (Finlay et al., 2011; Kyei, 2011; United Nations Children's Fund, 2012). Maternal education, besides income, is the most common determinants of child mortality in developing countries (Mosley and Chen, 1984). Other studies have shown that child mortality is influenced by sex of the child, mother's age at first birth, birth order, preceding birth interval among others (Muntuga, 2004; Omariba, et al., 2007; Kembo and Ginneken, 2009; Adepojuet al., 2012). Other factors include mother's education, birth interval with previous child, mother's standard of living index and marital status (Kumar and File, 2005; Goro, 2007). Further, baby boys are more likely to die before age five than girls (Hwa-Younget al., 2016). Further, household environmental characteristics do have significant impact on child mortality as lower mortality rates were experienced in households that had access to immunization, sanitation facilities, good and proper refuse and solid waste disposal facilities, access to drinking water and sanitation facilities, (Muntuga, 2004; Omariba, et al., 2007; Mesike and Mojekwu; 2012).

Previous studies had examined determinants of child mortality in Nigeria using 2008 Demographic Health Survey (Antaiet al., 2009; Olusanya, 2011; Kayodeet al; 2012; Mesike and Mojekwu, 2012; and Adepojuet al., 2012). Recently, Yaya et al., (2017) did a gendered analyses of child mortality using the pooled for the country (rural and urban) while this study analysed child mortality in rural Nigeria, with poor health infrastructure, which will give policy-specific information with respect to the child mortality endemic rural sector. It is noteworthy that except for Adepojuet al., (2012), the focus of these studies was not on rural Nigeria, which is well-known for poor health facilities. Further, Mesike and Mojekwu, (2012) used principal component analysis and simultaneous multiple regression for child mortality modelling in Nigeria, while Adepojuet al., (2012) and Yaya et al., (2017) used binary logistic regression to identify factors affecting child mortality in Nigeria. However, following the works of Wilson and Tisdell, 2002, this study adopted tobit regression model to assess spatial incidence and identify socio-economic pre-disposing factors of child mortality rate in rural Nigeria using 2013 Demographic Health Survey (DHS).

\section{Methodology}

Secondary data from Nigeria Demographic Health Survey (2013) was used for this study. Detailed information on the sampling design is available in the final reports (NPC 2014). The study was carried out in 2016/2017 and the data was first stratified into rural and urban, out of which rural population which is our concern for the purpose of this study was extracted out and subsequently divided into men and women considering their minimum age. The data was further stratified into six geopolitical zones of the country for effective capturing of the determinants of women empowerment and child mortality in the country. Information extracted for the study included education, age of the mother, gender, age at birth, wealth index, marital status, age at first marriage, child mortality rate, The targeted respondents for this study were 23403 rural mothers. The sampling technique followed a stratified two-stage cluster procedures. Data extracted for the study include education, age of the mother, gender, age at birth, wealth index, marital status, age at first marriage, maternity, child mortality rate, ratio of male to female mortality in under-five children. Descriptive and inferential statistics were used to profile incidence of child mortality while tobit regression model was used to identify the socio-economic correlates of child mortality and child mortality rate in rural Nigeria. Child mortality is the number of under-five mortality a woman has ever experienced while child mortality rate is the ratio of dead child to total number of children ever born.

Tobit model (Wilson and Tisdell, 2002). The Tobit model was given as: 


$$
\begin{aligned}
& Y_{i}=\alpha_{0}+\beta^{\prime} X_{i}+U_{i} \text { if RHS } \geq 0 \\
& Y_{i}=0 \text { otherwise. }
\end{aligned}
$$

$Y_{i}$ is number of under-five mortality or Child mortality rate, $X_{i}$ is a $\mathrm{K}^{*} 1$ vector of known variables. $\beta$ is a $K^{*} 1$ vector of unknown parameters. $U_{i}$ are the residuals with $E\left(U_{i}\right)=0$ and a common variance, $\sigma^{2}$. We also assume $U$ $\sim N\left(0, \sigma^{2}\right)$.

\section{RESULTS AND DISCUSSION}

One out of three male-headed households had experienced child mortality while one out of five female-headed households had experienced child mortality (Table 1). A highest percentage of the mothers were teenagers at first birth $(66.93 \%)$ and teenagers (19.83\%) at the time of data collection. This explains why about one out of every two mothers had no formal education. Thus, a typical rural mother was a teenager at first birth suggesting that most of the mothers were out of school in their teenage

Table1. Child mortality profile by household demographic characteristics

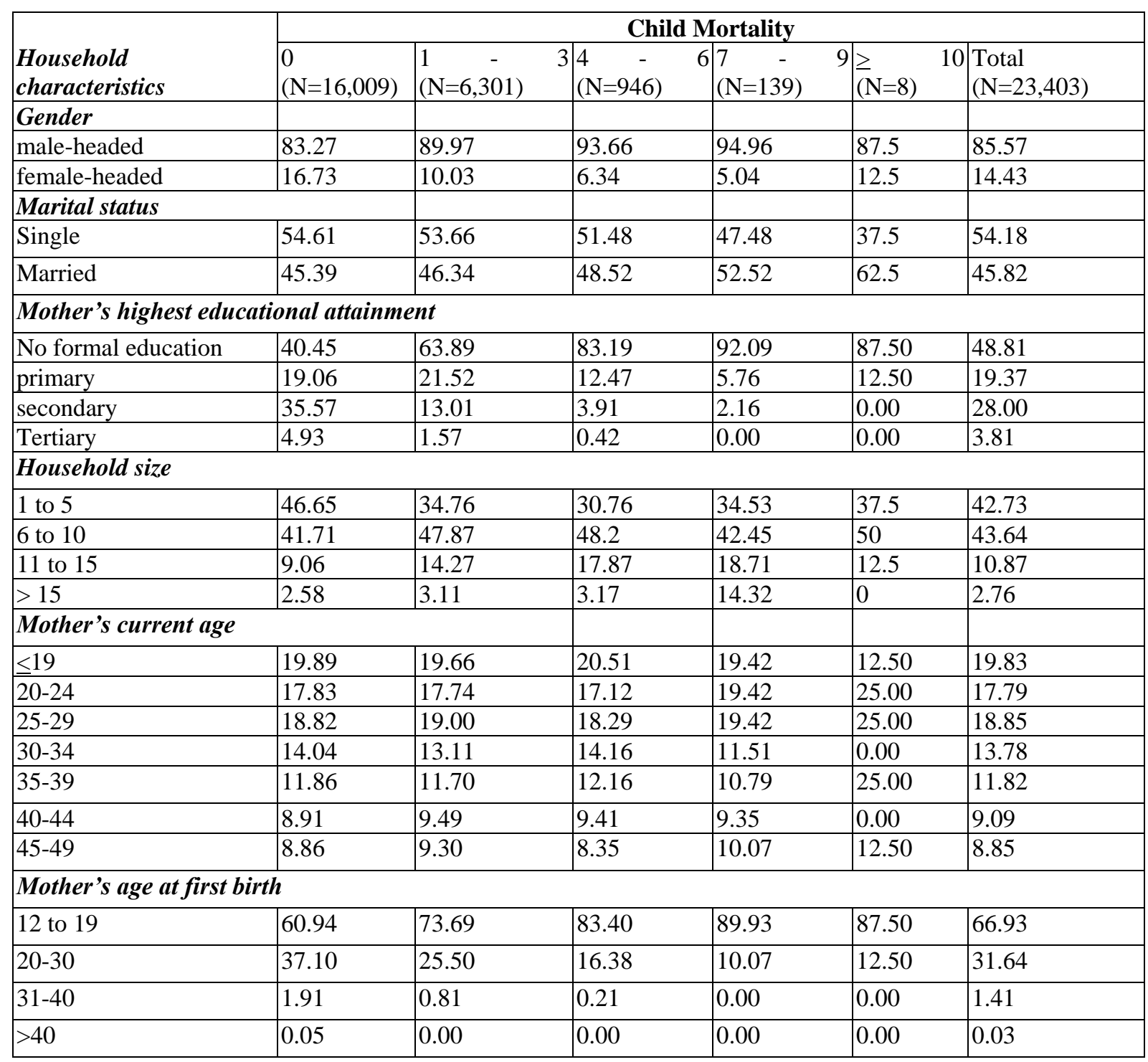

years with no formal education, which may negatively impact on their welfare and consequently increase the incidence of child mortality. Educated women are better informed about child health care system and can get better access to it. They can easily interact and communicate with health service providers to get required care for her as well as for her newborn (Bloom et al, 2001). That is, an educated woman is expected to utilize all available resources and information effectively which reduce the risk of child morbidity and mortality. In addition, incidence of child mortality was lower among mothers who had at most a child in the last three years than among those with multiple births or without birth control. Thus, low level of mothers' educational attainment accentuated child mortality in rural Nigeria. Prevalence of child mortality was highest among rural households Northwest (44.08\%) but least in the Southsouth (17.32\%) (Figure 1). 


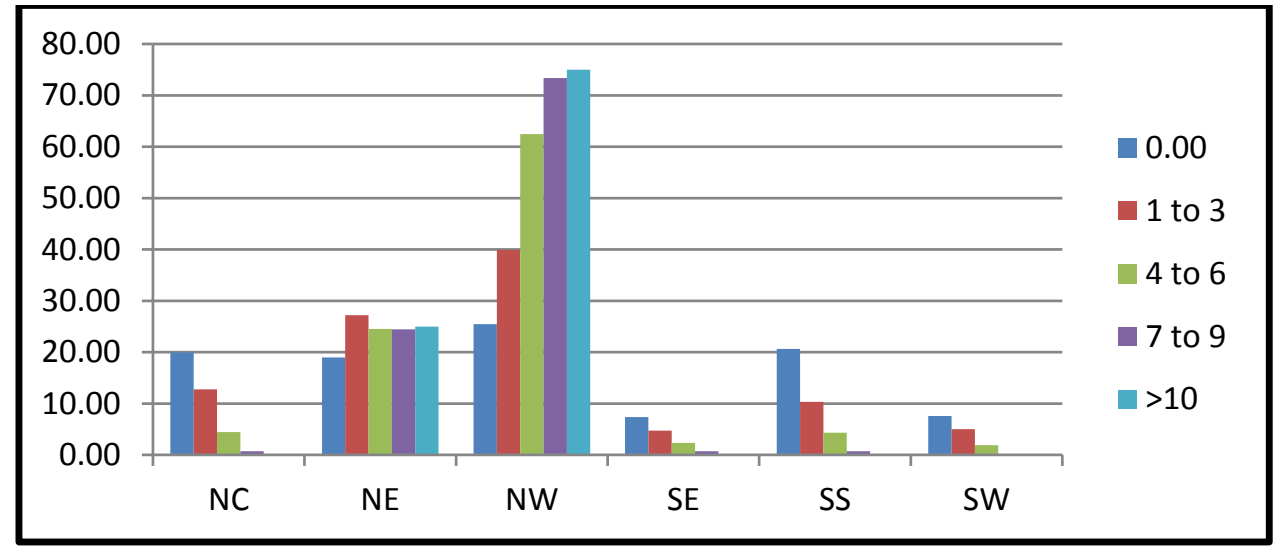

Figure1. Prevalence of child mortality in rural Nigeria

Further, $53.68 \%$ of under-five deaths were male children (Figure 2). Similarly, 22.48\% and $20.07 \%$ of male and female children, respectively did not live to see their fifth birthday (Table 2). This supports the findings of Adepojuet al., (2012) that there was a higher incidence of male-child mortality than femalechild mortality in 2008 in Nigeria. Child mortality also increased with short child spacing and all the households that had experienced multiple births $(>4)$ in the last five years had experienced child mortality.

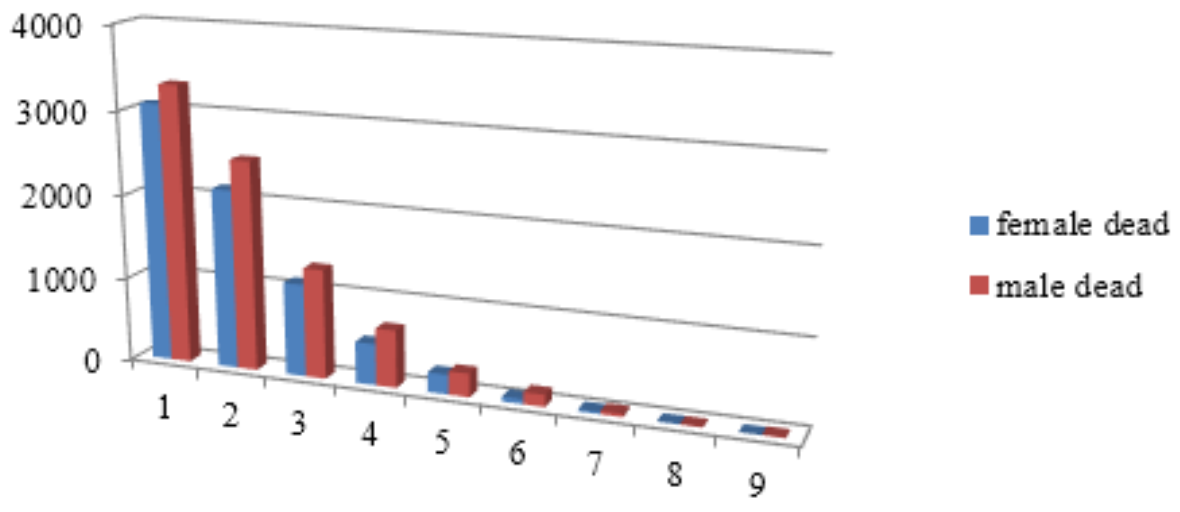

Figure2. Prevalence of child mortality by sex of the child

Table2. Child mortality profile by sanitation and wealth characteristics

\begin{tabular}{|c|c|c|c|c|c|c|}
\hline \multirow[b]{2}{*}{ Characteristics } & \multicolumn{6}{|c|}{ Child Mortality } \\
\hline & $0(\mathrm{~N}=16,009)$ & $1-3(\mathrm{~N}=6,301)$ & $4-6(N=946)$ & $7-9(N=139)$ & $\geq 10(\mathrm{~N}=8)$ & Total $(\mathrm{N}=23,403)$ \\
\hline \multicolumn{7}{|c|}{ Source of drinking water } \\
\hline Unsafe & 87.26 & 88.08 & 87 & 89.21 & 62.5 & 87.47 \\
\hline Safe & 12.74 & 11.92 & 13 & 10.79 & 37.5 & 12.53 \\
\hline \multicolumn{7}{|l|}{ Type of toilet } \\
\hline poor & 91.67 & 96.46 & 98.41 & 98.56 & 100 & 93.28 \\
\hline modern & 8.33 & 3.54 & 1.59 & 1.44 & 0 & 6.72 \\
\hline \multicolumn{7}{|l|}{ Wealth Index } \\
\hline Poorest & 21.65 & 35.01 & 46.09 & 61.87 & 75.00 & 26.49 \\
\hline poorer & 26.14 & 31.84 & 34.99 & 30.94 & 25.00 & 28.06 \\
\hline middle & 26.04 & 19.71 & 13.85 & 5.04 & 0.00 & 23.71 \\
\hline richer & 18.79 & 10.98 & 4.12 & 2.16 & 0.00 & 15.99 \\
\hline richest & 7.38 & 2.46 & 0.95 & 0.00 & 0.00 & 5.75 \\
\hline
\end{tabular}

Rural Nigeria is characterized by high level of poverty incidence characterized by poor access to basic necessities of life and low level of educational attainment (Obayelu and Awoyemi, 2010). Owing to endemic poverty in rural Nigeria, prevalence of child mortality was highest among poor households with no access

ARC Journal of Nutrition and Growth to good toilet facilities nor portable water (Table $3)$. This is in line with the findings of Adetoroand Amao (2014) that children born in households with low standard of living index (i.e. the poorest and poorer) experienced higher mortality than those who were born into households with high standard of living index. 
Table3. Child mortality profile by household birth characteristics

\begin{tabular}{|c|c|c|c|c|c|c|}
\hline \multirow[b]{2}{*}{$\begin{array}{l}\text { Households' demographic } \\
\text { characterististics }\end{array}$} & \multicolumn{6}{|c|}{ Child Mortality } \\
\hline & $\begin{array}{l}0 \\
(\mathrm{~N}=16,009)\end{array}$ & $\begin{array}{l}1-3 \\
(\mathrm{~N}=6,301)\end{array}$ & $\begin{array}{l}4-6 \\
(\mathrm{~N}=946) \\
\end{array}$ & $\begin{array}{l}7-9 \\
(\mathrm{~N}=139)\end{array}$ & $\begin{array}{l}\geq 10 \\
(\mathrm{~N}=8)\end{array}$ & $\begin{array}{l}\text { Total } \\
(\mathrm{N}=23,403)\end{array}$ \\
\hline \multicolumn{7}{|l|}{ Number of sons dead } \\
\hline 0.00 & 100.00 & 33.22 & 3.91 & 1.44 & 0.00 & 77.52 \\
\hline 1 to 3 & 0.00 & 66.78 & 78.64 & 34.53 & 12.50 & 21.37 \\
\hline 4 to 6 & 0.00 & 0.00 & 17.45 & 58.99 & 37.50 & 1.06 \\
\hline 7 to 9 & 0.00 & 0.00 & 0.00 & 5.04 & 50.00 & 0.05 \\
\hline \multicolumn{7}{|l|}{ Number of daughters dead } \\
\hline 0.00 & 100.00 & 41.63 & 7.82 & 0.72 & 0.00 & 79.93 \\
\hline 1 to 3 & 0.00 & 58.37 & 80.75 & 48.20 & 25.00 & 19.28 \\
\hline 4 to 6 & 0.00 & 0.00 & 11.43 & 48.20 & 62.50 & 0.77 \\
\hline 7 to 8 & 0.00 & 0.00 & 0.00 & 2.88 & 12.50 & 0.02 \\
\hline \multicolumn{7}{|l|}{ Births in the last five years } \\
\hline 0.00 & 50.00 & 24.39 & 40.38 & 52.52 & 62.50 & 42.73 \\
\hline 1 to 2 & 47.79 & 67.03 & 52.85 & 43.16 & 12.50 & 53.13 \\
\hline 3 to 4 & 2.21 & 8.52 & 6.66 & 3.60 & 25.00 & 4.11 \\
\hline 5 to 6 & 0.00 & 0.05 & 0.11 & 0.72 & 0.00 & 0.02 \\
\hline
\end{tabular}

\subsection{Determinants of Child Mortality across} the Six Geo-Political Zones

Results further showed that age, mothers' educational attainment, household size, marital status, mother's age at first birth, occupation, wealth index, sources of drinking water, place of delivery and toilet facility significantly influenced the probability that child mortality rate (Table 4). This is in line with the findings of Adepojuet al., (2012) that sex of the child, mother's age at first birth, birth order, preceding birth interval among others explain child mortality in Nigeria.

Mother's age of a rural household in the study area was found to be significant and negative; a unit increase in Mother's age among the rural dwellers' in the zones leads to 0.003 unit increase in child mortality. This could be as a result of high rate of teenage pregnancy in the zones especially in the North and ever increasing baby factories in the east thus increase the child mortality rates. This supports the findings of Rahman (2013), Jewell et al., (2014) that age was significant and negative in their respective study areas. Mothers' educational attainment reduced child mortality because the mother will be better informed about how the health care system functions and can get better access to it. Further, she can easily interact and communicate with health service providers to get required care for her as well as for her newborn (Bloom et al; 2001). That is, an educated woman is expected to utilize all available resources and information effectively which reduce the risk of child morbidity and mortality.
Sex of the household head was found negatively related to the likelihood of child mortality suggesting that child mortality was significantly higher among male-headed households than among female-headed households. This might be because a female household head would take prompt decision on the child health care without any permission from a man. Household size of a rural household was found to be significant and negative; a unit decrease in household size among the rural dwellers' in the country leads to 0.012 increase in child mortality. This implies that they do not have sufficient financial capacity and social amenities for the ante-natal and probably post-natal care for the mothers' and children procreated. Hence, among socioeconomic characteristics that contribute to child's survival is household size, access to electricity and wealth indices. The odds of child mortality increase with the decrease in the size of household. This may be because newly born may have more and better care in the extended families with more members in the household.

Wealth index for the poorer among rural women in the study area show that the wealth index of has a negative influence on child mortality among rich households relative to poor families. This is in line with a prior expectation that the poorer an individual is the less he or she will be able to take care of child not to talk of households. Child mortality was lower for those living in wealthier households (Muntago, 2004). On the contrary, a middle wealth index class in the study area shows that a unit increase in the wealth index of middle-class income earners among the households leads to 0.024 decrease in the child mortality. This implies that an average households in terms of finance which have 
access to nutrients, food and drugs that will prevent their under five years children from contacting through proper diagnosing in the hospital so as to provide necessary medicine in order to increase the child survival rate in the zones. Further, children born into middle income and rich families are most likely to survive more compared to those in poor families. This is because families with more wealth and income have ability to care for the mother and the baby, which may increase the chances of the survival of the newly born. Further, mother's age at first birth of a rural household in the study area was found to be significant and negative; a unit increase in mother's age at first birth reduced the likelihood of child mortality by 0.004 . This could be as a

Table4. Determinants of child mortality and child mortality rate result of high rate of teenage pregnancy in the zones especially in the North and ever increasing baby factories in the East. Use of orthodox places of delivery had a negative influence on child mortality. Further, residing in southwest reduced the log likelihood of child mortality but increased it by residing in the North east and North-west. These findings are consistent with the previous studies, Jewell et al., (2014) and Rahman 2013 that the most important predictors of infant mortality are a full gestational period, mother's educational attainment, marital status, and the type of hospital used for delivery antenatal care utilization, place of delivery, and mother's education.

\begin{tabular}{|c|c|c|c|c|}
\hline \multirow[t]{2}{*}{ Variables } & \multicolumn{2}{|c|}{ Child Mortality } & \multicolumn{2}{|c|}{ Child Mortality Rate } \\
\hline & $\begin{array}{l}\text { Marginal effect } \\
(\mathrm{dy} / \mathrm{dx})\end{array}$ & Standard Error & $\begin{array}{l}\text { Marginal effect } \\
(\mathrm{dy} / \mathrm{dx})\end{array}$ & Standard Error \\
\hline Gender & 0.2736 & 0.1629 & 0.0114 & 0.0297 \\
\hline $\begin{array}{l}\text { Household size } \\
\text { Age of mother }\end{array}$ & $0.0331 * * *$ & 0.0079 & -0.0005 & 0.0015 \\
\hline Mother's age at first birth & $-0.0942 * * *$ & 0.0076 & $-0.0158 * * *$ & 0.0014 \\
\hline Marital status & $0.4403 * * *$ & 0.1325 & 0.0389 & 0.0240 \\
\hline Mother's occupation & -0.0346 & 0.0492 & -0.0026 & 0.0091 \\
\hline Mother's education & $-0.0228 * * *$ & 0.0066 & $-0.0042 * * *$ & 0.0012 \\
\hline Husband's age & $0.0381 * * *$ & 0.0024 & $0.0054 * * *$ & 0.0004 \\
\hline \multicolumn{5}{|l|}{ Wealth indices } \\
\hline Poorest & $0.6244 * * *$ & 0.2041 & $0.1041 * * *$ & 0.0374 \\
\hline Poorer & $0.5967 * * *$ & 0.2007 & $0.1062 * * *$ & 0.0367 \\
\hline Middle & $0.3431 *$ & 0.1970 & $0.0662 * * *$ & 0.0349 \\
\hline Richer & 0.2612 & 0.1918 & 0.0572 & 0.0349 \\
\hline Type of toilet facility & 0.0164 & 0.1629 & 0.0051 & 0.0297 \\
\hline Give egg to child & $-0.0763 * *$ & 0.0352 & $-0.0122 *$ & 0.0064 \\
\hline Death sex ratio & $1.9610 * * *$ & 0.0465 & $0.2653 * * *$ & 0.0087 \\
\hline Drinking water & -0.0786 & 0.0777 & -0.0052 & 0.0143 \\
\hline No net & -0.0068 & 0.0632 & 0.0010 & 0.0117 \\
\hline Use untreated net & -0.0595 & 0.1810 & 0.0014 & 0.0333 \\
\hline \multicolumn{5}{|l|}{ Region } \\
\hline Northcentral & $-0.2131 *$ & 0.119 & -0.0139 & 0.0205 \\
\hline Northeast & $0.2057 *$ & 0.1106 & $0.0594 * * *$ & 0.0204 \\
\hline Northwest & $0.2714 * *$ & 0.1074 & $0.0647 * * *$ & 0.0198 \\
\hline Southeast & $0.3995 * * *$ & 0.1511 & $0.0684 * *$ & 0.0278 \\
\hline Southwest & 0.1039 & 0.1409 & 0.0196 & 0.0259 \\
\hline Number of observation & \multicolumn{2}{|c|}{7436} & \multicolumn{2}{|c|}{7436} \\
\hline Log likelihood & \multicolumn{2}{|c|}{-7672.1347} & \multicolumn{2}{|c|}{1854.21} \\
\hline Prob > chi2 & \multicolumn{2}{|c|}{0.0000} & \multicolumn{2}{|c|}{0.0000} \\
\hline Pseudo R ${ }^{2}$ & \multicolumn{2}{|c|}{0.1570} & \multicolumn{2}{|c|}{0.2264} \\
\hline
\end{tabular}

\section{CONCLUSION}

The study concluded that mother educational attainment, household size, mother's age at first birth, place of delivery; wealth index and regions were the significant variables for child mortality. Federal Ministry of Education needs to collaborate in order to reduce child mortality rate in rural Nigeria. Federal Ministry of Education should intensify campaign on girlchild education, especially in northern Nigeria while Federal and state ministries of health should intensify birth control campaign against large families, and short birth interval through 
reproductive health services in rural Nigeria. Both ministries need to fight teenage pregnancy in rural Nigeria through its inclusion in educational curriculum and extensive awareness programs. Poverty emerges as one of the obstacles to the reduction of child mortality. Respondents belong to poor families do not have ability to seek care for pregnant mother and her new born baby. Therefore, poverty eradication policy should be pursued effectively. In the short-run, special program targeting the poorest section of the community should be undertaken to provide necessary maternal and child healthcare services. There exists disparity in the distribution of infant mortality among the regions. Policies for the reduction of child mortality should be geo-political region-specific and allocation of resources should consider specific regional needs and degree of child mortality.

\section{ACKNOWLEDGEMENT}

Author is grateful to the National Bureau of Statistics, Nigeria for releasing the data for use.

\section{REFERENCES}

[1] Adepoju AO, Akanni O and Falusi AO. Determinants of Child Mortality in Rural Nigeria. World Rural Observ. 2012;4(2):38-45.

[2] Adetoro, G. W. and Amoo E. O. A statistical analysis of child mortality: evidence from Nigeria.Journal of Demography and Social Statistics, 2014: 1, (March):110-120.

[3] Antai D., Wedrén S., Bellocco R., Moradi T. Ethnic Disparities in Child Health in Nigeria: A Multilevel Analysis of Individual and Contextual Factors. Ethnicity and Inequalities in Health and Social Care. 2009;2(4):39-49. doi: $10.1108 / 17570980200900028$

[4] Bello, R.A. Determinants of infant and child mortality in the African Sub-Region, Political Science Review, 2002; 1:74-83

[5] Black, R.E., \& Li, Liu.Global Under Five Mortality: Where Do We Stand Today?Johns Hopkins, Bloomberg School of Public Health for the Child Health Epidemiology Reference Group of WHO and UNICEF2012.

[6] Bloom, S. S., Wypij, D., \& Gupta, M. D. (2001). Dimensions of women's autonomy and the influence on maternal health care utilization in a north Indian city. Demography, 38(1), 67-78.

[7] Finlay, E Jocelyn, Özaltin, Emre, Canning, David. The association of maternal age with infant mortality, child anthropometric failure, diarrhoea and anaemia for first births: evidence from 55 low- and middle-income countries. BMJ Open, 2011; 1(2) 2011. DOI:10.1136/ bmjopen-2011-000226. ISSN 2044-6055.
[8] Gambrah, P.P.\&Adzadu, Y. Using Markov Chain to predict the probability of rural and urban child mortality rates reduction in Ghana. International Journal of Scientific \& Technology Research,2013; 2(11):73-78. ISSN 2277-8616.

[9] Goro, I.M. 2007. The stalling child mortality in Ghana: Thecase of the three northern regions. Paper presented at the5th Conference of Union for Africa Population Studies(UAPS), Arusha, Tanzania, December 10-14 2007.

[10] Hong, R., \& Ruiz-Beltran, M. Impact of prenatal care on infant survival in Bangladesh. Maternal and child health journal, 2007; 11(2), 199-206.

[11] Hwa-Young, L., Dung, V.D., Sugy, C.,1 Oanh T.H.T. and Kien, G.T. Trends and determinants of infant and under-five childhood mortality in Vietnam, 1986-2011. Global Health Action 2016; 9: 10.3402/gha.v9.29312. doi: 10.3402/ gha.v9.29312

[12] G.A. Kayode, V.T. Adekanmbi, O.A. Uthman 2012.Risk factors and a predictive model for under-five mortality in Nigeria: evidence from Nigeria demographic and health survey. BMC Pregnancy Childbirth (2012), p.1012 (2012), p. 10

[13] Jewell, R. T., Martinez, J., \&Triunfo, P. (2014). Infant Mortality in Uruguay: The Effect of Socioeconomic Status on Survival. The Journal of Developing Areas, 48(2), 307-328.

[14] Kembo, J. and Ginneken, V. (2009). Determinants of infant and child mortality in Zimbabwe: Result of multivariate hazard analysis. Demographic Research 21 (13):367-384

[15] Kumar, P.P.and File, G. Infant and child mortality in Ethiopia: A statistical analysis approach, Ethiopian Journal of Education and Science, 2010; 5(2):51-7

[16] Kyei, A. Kwabena (2011). Socio - Economic Factors Affecting Under Five Mortality in SouthAfrica - An Investigative Study. Journal of Emerging Trends in Economics andManagement Sciences (JETEMS), Vol. 2, No. 2, 2011. Scholarlink Research Institute Journals. Pp104-110. ISSN: 2141-7024.

[17] Marx, M., Coles, C., Prysones-Jones, S., Johnson, C., Augustin, R., Mackay, N., Bery, R., Hammond, W., Nigmann, R., Sommerfelt, E., Lee Benntt, H.J., and Lambert, R. Child survival in Sub-Saharan Africa: Taking stock. Washington DC, USA:Support for Analysis and Research in Africa (SARA) Project.2005.

[18] Mesike, C.G., Mojekwu J. N. Environmental determinants of child mortality in Nigeria. Journal of Sustainable Development, 2012; 5(1): 65-75

[19] Mutunga, C. J., 2004. Environmental determinants of child mortality in Kenya. Kenya Institute for Public Policy Research and Analysis (KIPPRA), Nairobi, Kenya. 
[20] National Bureau of Statistics (NBS). Nigeria: Monitoring the situation of children and women. Nigeria Multiple Indicator Cluster Survey 2011Summary Report. National Bureau of Statistics, Abuja Nigeria. 2011.

[21] National Population Commission (NPC) [Nigeria] and ICF International. Nigeria Demographicand Health Survey 2013. Abuja, Nigeria, and Rockville, Maryland, USA: NPC and ICF International. 2014

[22] Obayelu O. A. and Awoyemi T.T. Spatial dimension of poverty in rural Nigeria. Journal of Development and Agricultural Economics. 2010;2(6) June 2010:231-244. ISSN 2006-9774

[23] Olusanya B.O. 2010. Child survival and child development in developing countries. Journal of Paediatrics and Child Health, 2011;47, 11: 845-846

[24] Omariba D. W. R., Beaujot R., Rajulton F. Determinants of Infant and Child Mortality in Kenya: An Analysis Controlling for Frailty Effects. Population Research and Policy Review. 2007;(3):299-321. doi:10.1007/ s11113-007-9031-z

[25] United Nations Children's Fund (2012). Levels and Trends in Child Mortality - Report
2012.Estimates Developed by the United Nations Inter-agency Group for Child Mortality Estimation. United Nations Children's Fund. 2012.

http://www.unicef.org/videoaudio/PDFs/UNIC EF_2012_child_mortality_for_web_0904.pdf.

[26] UNICEF/WHO Levels and trends in child mortality. Report 2013. 2014. http://www.who.int/maternal_child_adolescent/ documents/levels_trends_child_mortality_2013 .pdf?ua $=1$.

[27] Wilson, C. and Tisdell, C. OLS and Tobit Estimates: When is Substitution Defensible Operationally?" Economic Theory, Applications and Issues, Working Paper No. 15, The University of Queensland, Brisbane. 2002.

[28] World Bank World Development Indicators: Mortality World Bank Group. 2013. http://wdi.worldbank.org/table/2.21

[29] Yaya, S., Ekholuenetale, M., Tudeme, G., Vaibhav, S., Bishwajit, G. and Kadio, B. 2017. Prevalence and determinants of childhood mortality in Nigeria.BMC Public Health 17(1) . May 2017. Retrieved on 11 March, 2019 from https://doi.org/10.1186/s12889-017-4420-7

Citation: Oluwakemi Adeola Obayelu. Explaining Child Mortality in Rural Nigeria. ARC Journal of Nutrition and Growth. 2019;5(1):6-13. DOI: dx.doi.org/ 10.20431/2455-2550.0501002.

Copyright: (C) 2019 Authors. This is an open-access article distributed under the terms of the Creative Commons Attribution License, which permits unrestricted use, distribution, and reproduction in any medium, provided the original author and source are credited. 